\title{
REVIEWS
}

Adv Clin Exp Med 2014, 23, 1, 135-142

ISSN 1899-5276

(c) Copyright by Wroclaw Medical University

\author{
Aleksander Łukasiewicz ${ }^{1,2, A-D}$, Tomasz Drewa ${ }^{2, A, ~ D-F}$
}

\section{Synthetic Implants in Hernia Surgery}

${ }^{1}$ Department of Vascular Surgery, Regional Specialist Hospital in Grudziądz, Poland

2 Tissue Engineering Department, Nicolaus Copernicus University, Ludwik Rydygier Collegium Medicum in Bydgoszcz, Poland

A - research concept and design; B - collection and/or assembly of data; C - data analysis and interpretation;

$\mathbf{D}$ - writing the article; $\mathbf{E}$ - critical revision of the article; $\mathbf{F}$ - final approval of article; $\mathbf{G}$ - other

\begin{abstract}
Abdominal wall hernia correction is one of the most common surgical procedures. 85,000 hernia operations are performed in Poland each year. Modern techniques of abdominal wall reconstruction utilize surgical implants for fascial defect closure. In the 70s and the 80 s of the last century, these techniques gained widespread acceptance among surgeons. Significant improvement of results in terms of recurrences was observed. Treatment of large abdominal wall defects became possible. Three types of surgical implants were developed early: polipropylene $(\mathrm{PP})$, poliethylene (PE) and politetrafluoroethylene (PTFE). Unfortunately, negative effects of implanted material soon became apparent. Excessive native tissues inflammatory response to the implanted material, leading to multiple complications was observed. Recurrences due to fibrosis, chronic regional pain, stiffness of the operation site, intestinal adhesions and fistulas, infertility and infections were reported. In some cases the use of standard synthetic implant was contraindicated. Analyzing drawbacks of the standard hernia implants, the medical industry developed new materials to improve treatment results. The most popular, currently utilized synthetic materials, are presented in this review in the context of clinical results (Adv Clin Exp Med 2014, 23, 1, 135-142).
\end{abstract}

Key words: abdominal hernia, surgery, bioprosthesis.

The primary aim of abdominal hernia reconstruction is the closure of a fascia defect to avoid potentially deadly complications of hernia incarceration and to relieve symptoms accompanying the protrusion of abdominal viscera through the defective abdominal wall. According to the utilized surgical technique, closure under tension or tension-free repair can be distinguished [1].

Closure under tension requires direct approximation of fascia margins using a surgical suture. The suture line tension and intrinsic weakness of native tissues in hernia patients result in increased hernia recurrence rates, especially in large (over $5 \mathrm{~cm}$ diameter) fascia defects. Considering inferior treatment results, indications for this technique are currently confined to small abdominal and inguinal hernias and patients of a significant risk of operative site infection (e.g. strangulated hernia).

The tension-free repair of abdominal wall hernia requires a surgical implant to fill the fascia defect without tension. The idea of utilizing the surgical graft comes from the knowledge that hernia occurrence is only a local manifestation of general disorder that affects all the connective tissue in hernia patients. Abdominal wall fascias are defective and weakened comparing those in healthy individuals and therefore require additional support to assure favorable outcome. The awareness of external fascia support necessity in hernia treatment was already evident in late 80 s of the 19th century; however, the development of surgical techniques was hampered by the lack of adequate biomaterials until the second half of the 20th century. It was then that the first synthetic implants were utilized clinically in hernia reconstruction [2]. Currently, tension-free repair dominates hernia treatment in developed countries including Poland [3].

Properties of an ideal implant were described at early 50s of the last century and were updated according to expanding knowledge on this subject $[4,5]$. The following features were pointed out: 
- Sufficient mechanical strength

- Chemical stability

- Lack of carcinogenic properties

- Easy sterilization

- Ability to limit foreign body reaction

- Fabrication in required size and shape

- Infection resistance

- Biomechanical properties resembling native tissues.

Despite many years of laboratory and clinical research, the ideal implant production is still the "Holy Grail" of medical industry. Currently, 3 major types of implants are utilized in hernia surgery:

1. Standard non-absorbable synthetic implants.

2. Composite synthetic implants.

3. Bioimplants, mainly composed of derived from human or animal tissues collagen matrices.

The first 2 types, thanks to favorable properties and low costs, gained widespread acceptance in the surgical community.

\section{Standard Synthetic Implants}

Standard synthetic implants are currently the most popular prostheses utilized in hernia surgery. They were developed early, in the 50s and 60 s of the last century and vast experience in treatment was gained since then. Nowadays, 3 types of materials are utilized widely: polipropylene (PP), polyester (PET) and polytetrafluoroethylene (PTFE).

\section{Polypropylene Implants}

PP meshes, due to extensive surgical experience, unique properties and low costs are the most commonly utilized implants in hernia surgery [6]. Polypropylene is derived from polymerization of propylene, a derivative of propane. It is a hydrophobic, resistant to enzymatic degradation polymer that is usually manufactured in a form of monofilament mesh. It induces an intensive fibrous reaction of the surrounding tissues that results in the formation of a strong and resistant to hernia relapse scar. On the other hand, this process leads to significant (even $30 \%$ in some studies) mesh area reduction and sometimes hernia recurrence. PP is susceptible to oxidative stress and subsequent filament damage, a phenomenon occasionally observed on microscopy leads to reduced prosthesis durability [7].

Currently utilized PP meshes are divided into 2 categories: heavy-weight and light-weight; however, a strict distinction is problematic [8]. At first, the breakdown criterion was the weight. Implants over $80 \mathrm{~g}$ per $\mathrm{m}^{2}$ were referred to as heavy-weight, the rest was described as light-weight. It was soon recognized, however, that the implant properties depend not only on weight alone but also on its structure, compliance, elasticity and pore size. According to these criteria, the term heavy-weight was ascribed to stiff, non-elastic implants with small, below $1 \mathrm{~mm}$ pore size. Tensile strength of such implants significantly exceeds physiologic requirements (approximately $16 \mathrm{~N} / \mathrm{cm}$ ) [9]. Heavy weight implants induce excessive tissue reaction and fibrosis. This leads to increased stiffness of abdominal wall, frequent foreign body sensation and chronic pain. Light-weight meshes have a larger, over $1 \mathrm{~mm}$, pore diameter. They are readily incorporated and induce less inflammatory reaction than standard heavy-weight grafts. The tensile strength is similar to physiologic and elasticity is significantly greater than in standard implants (20-35\% elongation under physiologic stress). The stiffness of the abdominal wall is less pronounced when light-weight grafts are utilized in hernia reconstruction. Foreign body sensation and chronic pain are reduced. Patients report less consumption of analgesics at the early postoperative period, quicker ambulation and return to work [10].

However, light-weight prostheses are not without drawbacks. There are reports that reduced tensile strength has a negative impact on the hernia recurrence and migration rate [11]. Studies were published that link the use of light-weight prostheses with reduced male fertility and increased peritoneal adhesions after operation [12].

Polipropylene is relatively resistant to infection. Monofilament mesh structure and large filament interstices allow for easy penetration of antibiotic and host immune cells as well as reduce the adhesion of bacteria to the mesh structure. Debridement with systemic antibiotic is a popular treatment modality of a limited mesh infection. Partial excision of macroscopically infected portion of the implant was also a suggested effective measure in such situations [13]. Currently, diverse types of polypropylene implants prepared for different clinical scenarios are available for surgeons.

\section{Polyester Implants}

Another synthetic polymer widely used in hernia surgery is polyester (its chemical name is poly(ethylene terephthalate)). It is synthesized through a polycondensation reaction of its monomers (bis- $\beta$-hydroxyterephthalate). It is more biostable than PP and is less vulnerable to oxidative stress than both PP and PTFE [14]. It is produced in a form of multifilament, hydrophilic mesh that 
readily adapts to the natural curvature of the abdominal wall. PET implants induce significant fibrotic reaction of surrounding tissues that facilitates permanent implant incorporation. Compared to PP meshes, PET prostheses possess superior mechanical features especially pliancy that makes the implantation technique easier. They are less prone to postoperative retraction, a process that is significant in PP implants. If used intraperitoneally, they induce extensive adhesions with viscera and, therefore, such placement is contraindicated [15]. Some authors reported increased susceptibility of PET implants to infection and increased rate of intestinal bowel fistula while comparing them with PP meshes [16]. Standard PET prostheses are mainly used in open surgical techniques that do not involve abdominal cavity e.g. Lichtenstein inguinal hernia correction [17].

\section{Polytetrafluoroethylene Implants}

Polytetrafluoroethylene (PTFE) is a synthetic polymer produced in the process of polymerization of tetrafluoroethylene. PTFE is hydrophobic: neither water nor water-containing substances wet PTFE, as fluorocarbons demonstrate mitigated London dispersion forces due to the high electronegativity of fluorine. This property determines the resistance of PTFE implants to the formation of adhesions with abdominal viscera [18]. It is non-reactive, partly because of the strength of carbon-fluorine bonds. Stability of PTFE implants is similar to that offered by PP meshes. Fibers in the PTFE prostheses are closely packed (pores below $75 \mathrm{~nm}$ ). Therefore, they are considered micropore implants that are rather encapsulated than penetrated by fibroblasts after implantation. During the healing processes, connective tissue forms a fibrous envelope around the whole implant that subsequently contracts decreasing the implant surface causing folding of the prosthesis [19]. This may lead to the implant malfunction and an increased recurrence rate that reaches $20 \%$ after ventral hernia repairs [20]. In the treatment of abdominal wall defects, PTFE prostheses have been utilized for many years. Thanks to their specific anti-adhesive properties, they are used when contact of the implant with viscera is anticipated and when intraperitoneal techniques of hernia correction are utilized. A serious drawback of PTFE prostheses is their relative susceptibility to infection. Some series reported even over $10 \%$ of implant-related infections [21].

\section{Modern Synthetic Implants in Abdominal Wall Reconstructions}

Application of the above-mentioned standard surgical synthetic implant in potentially contaminated operative field carries a high risk of implant infection, abscess or purulent fistula formation, sometimes, subsequent serious complications and even death. Furthermore, PP and PET implants, if placed in peritoneal cavity, are prone to visceral adhesion formation, which subsequently may lead to ileus or enteric fistula. The quest for a safe and effective hernia implant has yielded a production of numerous new biomaterials with modified properties to achieve better results.

These new biomaterials can be generally assigned to one of 2 classes:

A. Absorbable surgical implants.

B. Composite implants that consist of at least 2 components:

- stable and nonabsorbable (most often PP), that is permanent scaffold ensuring integrity of the implant and adequate tensile strength.

- anti-adhesive (either absorbable or not) that protects the implant from adhesion formation and in some implants serves as an additional temporary scaffold that reduces the amount of nonabsorbable component while maintaining the structural strength facilitating implantation.

\section{Absorbable Synthetic Implants}

The major component of absorbable synthetic implants is a polymer of polyglycolic acid (PGA) $\left(\right.$ Dexon $\left.^{\mathrm{TM}}\right)$ sometimes utilized as copolymer with polylactic acid (PLA) (poly(lactic-co-glycolic acid) (Vicryl $^{\mathrm{TM}}$, Polyglactin $910^{\mathrm{TM}}$ ). It is synthesized in a process of polycondensation or ring-opening polymerization (the latter process yields higher molecular mass form and is predominantly used). PGA is characterized by hydrolytic instability owing to the presence of the ester linkage in its backbone. It is produced in a form of knitted meshe that is entirely absorbed within 90 to 180 days. PGA implants are pliable, easily conforming to the required curvature, the feature improving handling and implantation. They are utilized for temporary closure of vast abdominal wall defects that cannot be managed otherwise (e.g. trauma, surgical complications, multiple laparotomies, abdominal compartment syndrome) [22, 23]. Such a strategy avoids 
the "open abdomen" treatment and has many advantages. It reduces the risk of complications in the peritoneal cavity and frequency of intestinal fistula as well as abates wound edges retraction that complicates the definite closure of abdominal wound. The application of an absorbable implant, deferring the final procedure, allows the definite treatment to be performed for a patient in better general and local conditions and with a decreased risk of significant complications [24]. PGA prostheses are often utilized in conjunction with negative pressure wound therapy systems, since they are water permeable. This strategy further improves treatment results in complicated cases. Yet another distinctive feature of absorbable meshes, contrary to permanent ones, is that they do not require removal in case of infection.

\section{Composite Implants}

Composite implants are utilized in various clinical scenarios. The most popular indications for application are:

- when intraperitoneal on-lay mesh procedure (IPOM) is performed to correct abdominal wall hernia. This technique facilitates the surgical procedure since no extensive preperitoneal dissection is required to secure the implant in place. It also reduces the duration of the procedure and decreases the risk of complications
- it is impossible to interpose the implant and abdominal viscera with a layer of native tissues, like in extensive abdominal wall defects

- when it is paramount to reduce the amount of permanent synthetic material in the wound to reduce probability of chronic pain as in case of inguinal herniorrhaphy.

Composite implants can be generally classified into one of 2 groups:

- the first, partially absorbable, where a nonabsorbable scaffold (most often PP) is coated with a layer of absorbable polymer. Such a coating increases the tensile strength of the implant at the moment of implantation, allowing a reduced amount of permanent material in the wound. Further, it protects the implant material when it comes in contact with viscera in the case of intraabdominal placement. The nonabsorbable component is then encased with connective tissue fibers by the time the coating is completely absorbed.

- the second, entirely nonabsorbable, with diverse inner and outer surface. The outer (fascial) surface is composed of material that has properties (either intrinsic or structural) inducing connective tissue cells migration and enhancing fibrosis. The inner (visceral) surface is smooth, resistant to adhesions formation and most often composed of PTFE. Such implants are used in the IPOM procedures (Table 1).

Table 1. Composite implants utilized in humans

\begin{tabular}{|c|c|c|}
\hline Trade name & Type & Composition \\
\hline 4DDome ${ }^{\circledR}$ & composite, partially absorbable & PP/Poly-L-lactic acid \\
\hline Composix $^{\circledR}$ & composite, nonabsorbable & $\mathrm{PP} / \mathrm{PTFE}$ \\
\hline C-Qur ${ }^{\circledR}$ & composite, partially absorbable & PP/omega- 3 fatty acids \\
\hline DualMesh $^{\circledR}$ & composite, nonabsorbable & $\begin{array}{l}\text { Macropore PTFE/ } \\
\text { micropore PTFE }\end{array}$ \\
\hline Glucamesh $^{\circledR}$ & composite, partially absorbable & $\mathrm{PP} /$ beta-D-glucan \\
\hline Parietene composite ${ }^{\circledR}$ & composite, partially absorbable & $\begin{array}{l}\text { PP/bovine atelocollagen, poly- } \\
\text { ethylene glycol, glycerol }\end{array}$ \\
\hline Parietex composite ${ }^{\circledR}$ & composite, partially absorbable & $\begin{array}{l}\text { PET/bovine atelocollagen, poly- } \\
\text { ethylene glycol, glycerol }\end{array}$ \\
\hline Proceed $^{\circledR}$ & composite, partially absorbable & $\begin{array}{l}\mathrm{PP} / \text { polydioxanone }+ \text { regenerated } \\
\text { cellulose }\end{array}$ \\
\hline Sepramesh ${ }^{\circledR}$ & composite, partially absorbable & $\begin{array}{l}\mathrm{PP} / \text { sodium hyaluronate }+ \text { car- } \\
\text { boxymethylcellulose }\end{array}$ \\
\hline Ultrapro $^{\circledR}$ & composite, partially absorbable & $\mathrm{PP} /$ poliglecaprone \\
\hline
\end{tabular}




\section{Partially Absorbable Composite Implants}

It is important to realize that partially absorbable implants vary among themselves in many ways: chemical composition, 3 dimensional structure, weight of permanent material, absorption time of absorbable component. Numerous animal studies were performed to compare these materials. Also, much clinical research comparing standard prostheses was done to confirm favorable outcomes ( $\mathrm{Ta}$ ble 2). Clinical experience indicates that composite implants are a valuable alternative to standard surgical prostheses utilized in standard surgical treatment. They are essential in the latest minimally invasive surgical techniques, such as single incision laparoscopic surgery (SILS) or natural orifice transluminal endoscopic surgery (NOTES). Early and mid-term clinical results indicate that the reduction of the amount of permanent component in the composite implants benefits the treatment. It abates the frequency and intensity of postoperative pain and allows quicker mobilization and faster convalescence. Actual benefits of reduced discomfort extend to even 6 months of postoperative period [27, 31].

Undoubtedly, a significant advantage of the partially absorbable implants, when compared with standard polypropylene surgical meshes, is the reduced influence on abdominal wall motility and elasticity. Experimental studies revealed that abdominal wall elongates approximately $11-32 \%$ under physiologic tension (approximately $16 \mathrm{~N} / \mathrm{cm}$ ). If high pressure is applied, the difference in dimensions may reach even $100 \%$ [38]. In such circumstances, implantation of standard, rigid prosthesis induces significant tension at the fixation points. This leads to increased inflammation and fibrosis and - as a result - rigidity of abdominal wall, foreign body sensation, chronic pain and possibility of recurrence. Modern composite implants in most cases pose elasticity comparable to that of the abdominal wall. This allows the incorporation of the prostheses without excessive tension and fibrosis, which probably determines improved early postoperative course. Certainly, it is the structure and amount of the permanent component that affects long-term operation outcomes but a significant reduction of the non-absorbable scaffold would be difficult without absorbable component reinforcing it at the time of surgery [39].

\section{Non-absorbable Composite Implants}

Basic structural component of non-absorbable implants is PTFE. Its continuous layer on the visceral side of the prosthesis determines its anti- adhesive properties and allows safe intraperitoneal placement. The outer layer varies in the composition. In some grafts it also consists of PTFE but in such a case the outer surface of the graft is rough and wrinkled, with larger pores to allow some infiltration of the native connective tissue to reinforce defect correction (e.g. Dualmesh ${ }^{\mathrm{TM}}$ ). In others, the outer layer is made of polypropylene, a polymer inducing fibrosis and incorporation of the prosthesis (e.g. Composix ${ }^{\mathrm{TM}}$ ) (Table 1). Clinical results of these grafts application were compared in the clinical trial by Bondi et al. [40]. Despite significant differences in handling and rigidity in favor of Dualmesh ${ }^{\mathrm{TM}}$, results were similar with both implants. According to these authors, the final outcome of the abdominal wall defect correction depends less on the type of implant but rather on the meticulous surgical technique especially adherence to current recommendations of $4 \mathrm{~cm}$ excess of the prosthesis to secure wall defect.

Modern synthetic composite implants allow further development of surgical minimally invasive techniques. A surgeon is no longer obligated to perform extensive surgical dissection of the abdominal wall to assure proper prosthesis coverage by native tissues, since the risk of visceral adhesions and complications is significantly diminished. It shortens the duration of operation, decreases postoperative pain, allows rapid postoperative ambulation and early return to work. This way despite increased costs of the composite grafts, the overall economic impact is favorable.

\section{Summary}

Over 60 years of development of surgical implants utilized in abdominal defect reconstructions has yielded a myriad of ready-available synthetic composite implants. These implants consisting of at least 2 components have revolutionized surgical treatment. Especially in the last 20 years a burst of different hernia implants has been observed. New, minimally invasive techniques emerged and tremendous progress in treatment was observed. Nowadays, it is possible to individualize surgical treatment of abdominal hernia defects according to actual need and preferences of the patients. Further improvement is expected in the field of biomechanical compatibility of the grafts, surgical handling and infection resistance. It is stimulated by progress in basic sciences on one hand and the constant demand of improved treatment results of patients and health care providers on the other. 


\begin{tabular}{|c|c|c|c|c|c|c|c|c|c|c|c|c|c|}
\hline $\begin{array}{l}\vec{\Xi} \\
\text { घี } \\
\dot{\Xi}\end{array}$ & 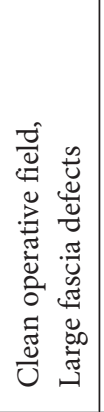 & 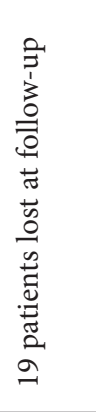 & 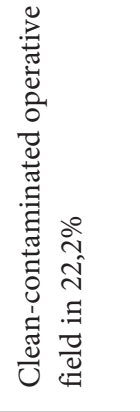 & 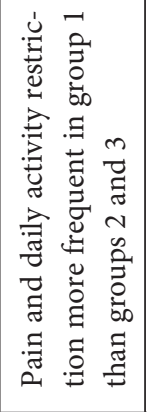 & 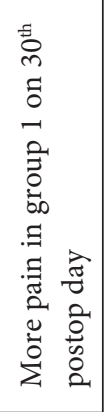 & 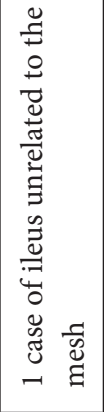 & 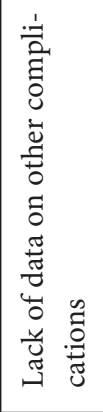 & 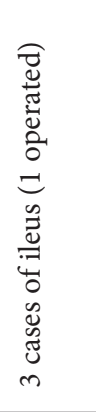 & 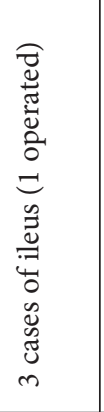 & 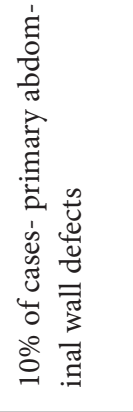 & 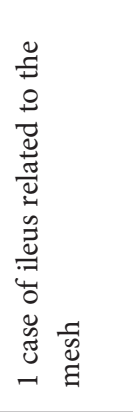 & 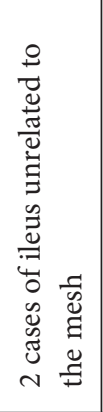 & 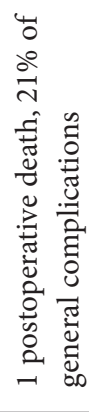 \\
\hline 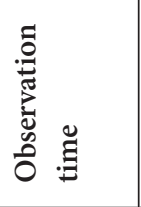 & 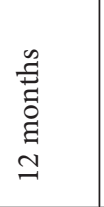 & 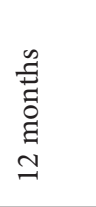 & 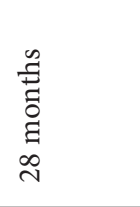 & 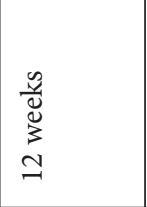 & 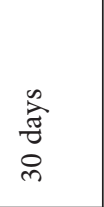 & $\begin{array}{l}\tilde{y} \\
\tilde{\Xi} \\
0 \\
\Xi \\
8\end{array}$ & 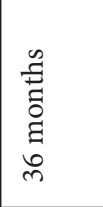 & 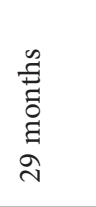 & 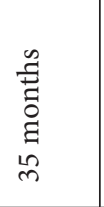 & 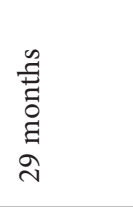 & 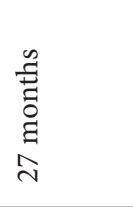 & 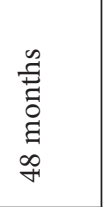 & $\overleftrightarrow{z}$ \\
\hline 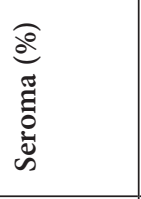 & $\stackrel{\infty}{\infty}$ & 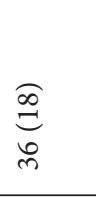 & $\begin{array}{l}\underset{\hat{\sigma}}{\sigma} \\
\stackrel{\overbrace{}}{6}\end{array}$ & $\overleftrightarrow{z}$ & $\overleftrightarrow{z}$ & $\widehat{\widehat{N}}$ & $\overleftrightarrow{z}$ & $\begin{array}{l}\underset{\infty}{+\infty} \\
\stackrel{i}{i}\end{array}$ & $\underset{-}{\stackrel{\sigma}{\Xi}}$ & $\underset{n}{\stackrel{f}{\stackrel{f}{i}}}$ & 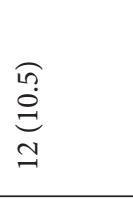 & 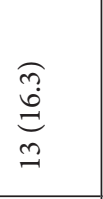 & $\begin{array}{l}\sqrt[\pi]{n} \\
\underset{H}{n}\end{array}$ \\
\hline 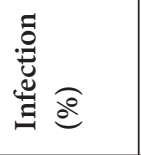 & $\underset{\forall}{\overparen{F}}$ & $\underset{\sim}{\Xi}$ & 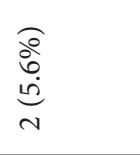 & $\overleftrightarrow{z}$ & $\overleftrightarrow{z}$ & 0 & 艺 & 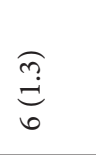 & $\underset{\sim}{\stackrel{\overbrace{}}{d}}$ & $\underset{-1}{0}$ & 0 & 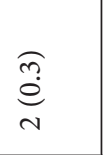 & $\begin{array}{l}\widehat{\vec{d}} \\
\overrightarrow{0}\end{array}$ \\
\hline 彥 & $\underbrace{6}_{0}$ & $\underset{\forall}{\widehat{d}}$ & 0 & $\overleftrightarrow{z}$ & $\overleftrightarrow{z}$ & $\begin{array}{l}\stackrel{\overparen{n}}{\hat{n}} \\
\stackrel{\Xi}{=}\end{array}$ & 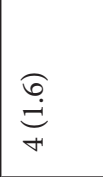 & $\stackrel{\widehat{\widetilde{q}}}{\stackrel{0}{*}}$ & 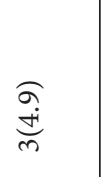 & 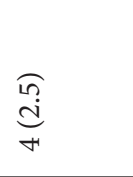 & 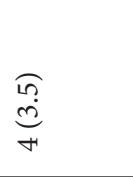 & 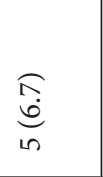 & $\begin{array}{l}\text { స్ } \\
\text { ळ్ }\end{array}$ \\
\hline 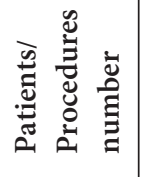 & $\nsubseteq$ & ڤે & $\stackrel{n}{n}$ & 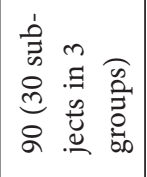 & $\begin{array}{l}\text { ্ָ } \\
\stackrel{d}{d} \\
\text { f }\end{array}$ & ্̊ণి & $\stackrel{\mathcal{I}}{\mathrm{I}}$ & 告 & $\vec{b}$ & $\stackrel{\infty}{\triangleq}$ & $\stackrel{\Xi}{\Xi}$ & $\triangleright$ & $\underset{\infty}{\infty}$ \\
\hline 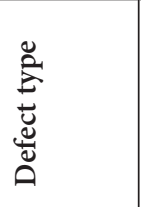 & 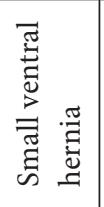 & 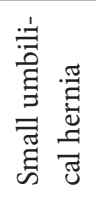 & 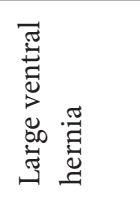 & 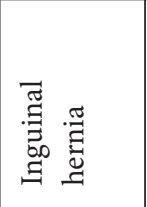 & 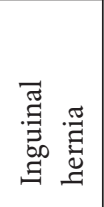 & 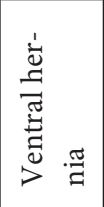 & 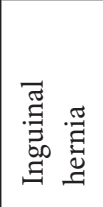 & 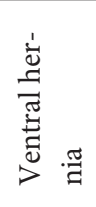 & 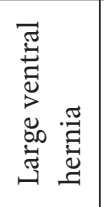 & 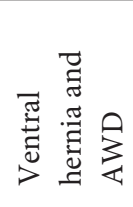 & 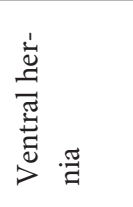 & 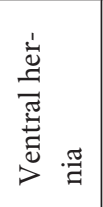 & 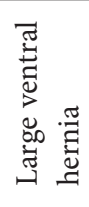 \\
\hline 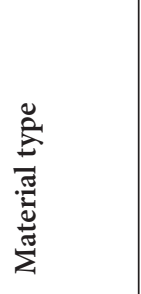 & 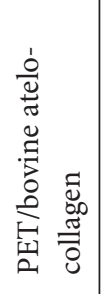 & 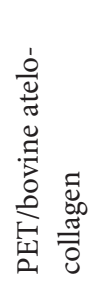 & 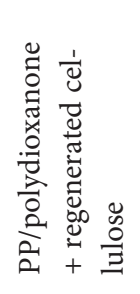 & 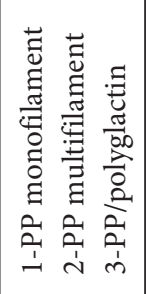 & 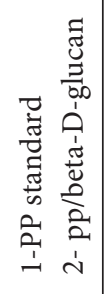 & 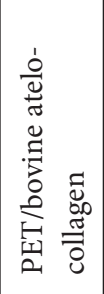 & 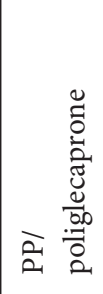 & 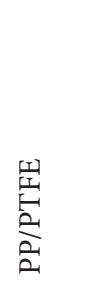 & 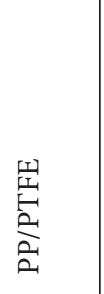 & 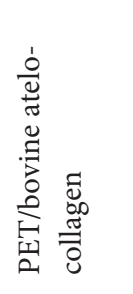 & 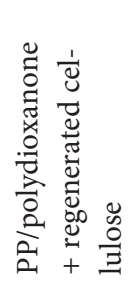 & 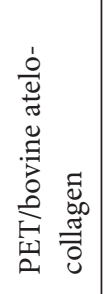 & 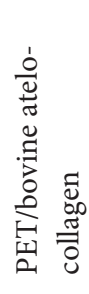 \\
\hline 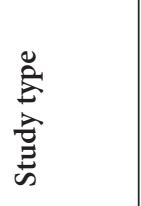 & 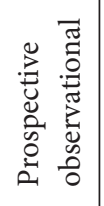 & 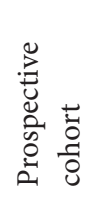 & 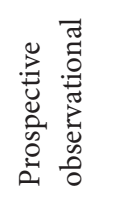 & 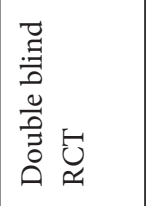 & 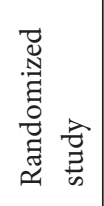 & 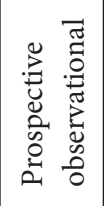 & 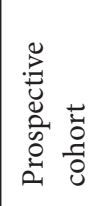 & 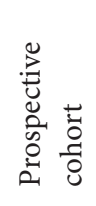 & 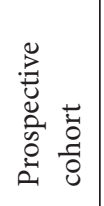 & 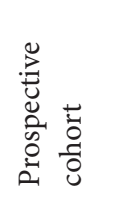 & 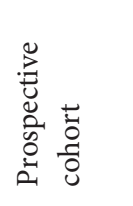 & 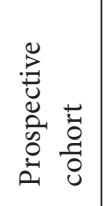 & 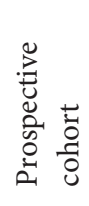 \\
\hline 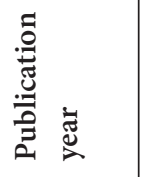 & $\stackrel{\circ}{\stackrel{\sim}{~}}$ & ષ્ণ & $\overrightarrow{\text { 亏े }}$ & ๕ั̀ & $\vec{\nabla}$ & $\stackrel{\circ}{\stackrel{\sim}{\sim}}$ & ठें & 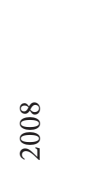 & ڤેे & \&ั่ & ठे̀े & ڤి & $\overrightarrow{\text { సे }}$ \\
\hline 泀 & 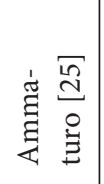 & 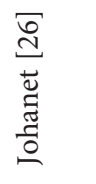 & $\frac{\sqrt{\mathrm{I}}}{\stackrel{\Xi}{\Xi}}$ & 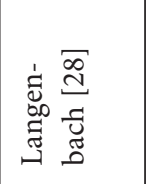 & 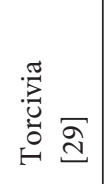 & 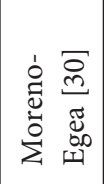 & 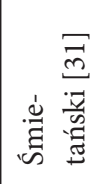 & 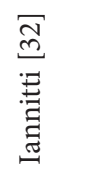 & 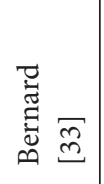 & $\begin{array}{l}\frac{F}{m} \\
\vec{\Xi} \\
0\end{array}$ & 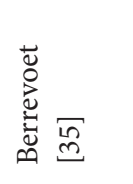 & 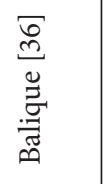 & 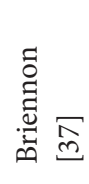 \\
\hline
\end{tabular}




\section{References}

[1] Kingsworth A, LeBlanc K: Hernias: inguinal and incisional. Lancet 2003, 362, 1561-1571.

[2] Usher FC, Fries JG, Ochsner JL, Tuttle LL Jr: Marlex mesh, a new plastic mesh for replacing tissue defects. Clinical studies. Arch Surg 1959, 78, 138-145.

[3] Narodowy Fundusz Zdrowia - strona internetowa: NFZ statystyka JGP. http://prog.nfz.gov.pl/jgp/KatalogJGP. aspx. access on 21.05.2012.

[4] Cumberland VH: A preliminary report on the use of a prefabricated nylon weave in the repair of ventral hernia. Med J Aust 1952, 1, 143-144.

[5] Hamer-Hodges DW, Scott NB: Surgeon's workshop. Replacement of an abdominal wall defect using expanded PTFE sheet (Gore-tex). J R Surg Edinb 1985, 30, 65-67.

[6] Shankaran V, Weber DJ, Reed RL 2nd, Luchette FA: A review of available prosthetics for ventral hernia repair. Ann Surg 2011, 253, 16-26.

[7] Mary C, Marois Y, King MW, Laroche G, Douville Y, Martin L, Guidoin R: Comparison of the in vivo behavior of polyvinylidene fluoride and polypropylene sutures used in vascular surgery. ASAIO J 1998, 44, 199-206.

[8] Bringman S, Conze J, Cuccurullo D, Deprest J, Junge K, Klosterhalfen B, Parra-Davila E, Ramshaw E, Schumpelick V: Hernia repair: the search for ideal meshes. Hernia 2010, 14, 81-87.

[9] Klinge U, Klosterhalfen B, Birkenhauer V, Junge K, Conze J, Schumpelick V: Impact of polymer pore size on the interface scar formation in a rat model. J Surg Res 2002, 103, 208-214.

[10] Smietański M, Bury K, Smietańska IA, Owczuk R, Paradowski T; Polish Hernia Study Group: Five-year results of a randomised controlled multi-centre study comparing heavy-weight knitted versus low-weight, non-woven polypropylene implants in Lichtenstein hernioplasty. Hernia 2011, 15, 495-501.

[11] Chui LB, Ng WT, Sze YS, Yuen KS, Wong YT, Kong CK: Prospective, randomized, controlled trial comparing lightweight versus heavyweight mesh in chronic pain incidence after TEP repair of bilateral inguinal hernia. Surg Endosc 2010, 24, 2735-2738.

[12] Peeters E, Spiessens C, Oyen R, De Wever L, Vanderschueren D, Penninckx F, Miserez M: Laparoscopic inguinal hernia repair in men with lightweight meshes may significantly impair sperm motility: a randomized controlled trial. Ann Surg 2010, 252, 240-246.

[13] Medberry CJ, Tottey S, Jiang H, Johnson SA, Badylak SF: Resistance to infection of five different materials in a rat body wall model. J Surg Res 2012, 173, 38-44.

[14] Cozad MJ, Grant DA, Bachman SL, Grant DN, Ramshaw BJ, Grant SA: Materials characterization of explanted polypropylene, polyethylene terephthalate, and expanded polytetrafluoroethylene composites: spectral and thermal analysis. J Biomed Mater Res B Appl Biomater 2010, 94, 455-462.

[15] Burger JW, Halm JA, Wijsmuller AR, ten Raa S, Jeekel J: Evaluation of new prosthetic meshes for ventral hernia repair. Surg Endosc 2006, 20, 1320-1325.

[16] Leber GE, Garb JL, Alexander AI, Reed WP: Long-term complications associated with prosthetic repair of incisional hernias. Ann Surg 1998, 133, 378-382.

[17] Poghosyan T, Veyrie N, Corigliano N, Helmy N, Servajean S, Bouillot JL: Retromuscular mesh repair of midline incisional hernia with polyester standard mesh: monocentric experience of 261 consecutive patients with a 5-year follow-up. World J Surg 2012, 36, 782-790.

[18] Voskerician G, Rodriguez A, Gingras PH: Macroporous condensed poly(tetra fluoro-ethylene). II. In vivo effect on adhesion formation and tissue integration. J Biomed Mater Res A 2007, 82, 426-435.

[19] Orenstein SB, Saberski ER, Kreutzer DL, Novitsky YW: Comparative analysis of histopathologic effects of synthetic meshes based on material, weight, and pore size in mice. J Surg Res 2012, 176, 423-429.

[20] Trupka AW, Schweiberer L, Hallfeldt K, Waldner H: Management of large abdominal wall hernias with foreign implant materials (Gore-Tex patch). Zentralbl Chir 1997, 122, 879-884.

[21] McGinty JJ, Hogle NJ, McCarthy H, Fowler DL: A comparative study of adhesion formation and abdominal wall ingrowth after laparoscopic ventral hernia repair in a porcine model using multiple types of mesh. Surg Endosc 2005, 19, 786-790.

[22] Sriussadaporn S, Sriussadaporn S, Pak-art R, Krittayakirana K, Prichayuhd S: Planned ventral hernia with absorbable mesh: a life-saving method in relaparotomy for septic abdomen. J Med Assoc Thai 2010, 93, 449-456.

[23] Prichayudh S, Sriussadaporn S, Samorn P, Pak-Art R, Sriussadaporn S, Kritayakirana K, Capin A: Management of open abdomen with an absorbable mesh closure. Surg Today 2011, 41, 72-78.

[24] Sikkink CJ, Vries de Reilingh TS, Malyar AW, Jansen JA, Bleichrodt RP, van Goor H: Adhesion formation and reherniation differ between meshes used for abdominal wall reconstruction. Hernia 2006, 10, 218-222.

[25] Ammaturo C, Bassi UA, Bassi G: Outcomes of the open mesh repair of large incisional hernias using an intraperitoneal composite mesh: our experience with 100 cases. Updates Surg 2010, 62, 55-61.

[26] Johanet H, Dabrowski A, Hauters P; Club Coelio: Repair of large abdominal wall defects using the Proceed surgical mesh with open intra-peritonium onlay method. Hernia 2006, 10, 414-418.

[27] Liu F, Li J: Laparoscopic cure of small ventral hernias with composite mesh. Saudi Med J 2011, 32, 504-509.

[28] Langenbach MR, Schmidt J, Zirngibl H: Comparison of biomaterials: three meshes and TAPP for inguinal hernia. Surg Endosc 2006, 20, 1511-1517.

[29] Torcivia A, Vons C, Barrat C, Dufour F, Champault G: Influence of mesh type on the quality of early outcomes after inguinal hernia repair in ambulatory setting controlled study: Glucamesh ${ }^{\oplus}$ vs Polypropylene ${ }^{\oplus}$. Langenbecks Arch Surg 2011, 396, 173-178. 
[30] Moreno-Egea A, Bustos JA, Girela E, Aguayo-Albasini JL: Long-term results of laparoscopic repair of incisional hernias using an intraperitoneal composite mesh. Surg Endosc 2010, 24, 359-365.

[31] Smietański M, Bigda J, Zaborowski K, Worek M, Sledziński Z: Three-year follow-up of modified Lichtenstein inguinal hernioplasty using lightweight poliglecaprone/polypropylene mesh. Hernia 2009, 13, 239-242.

[32] Iannitti DA, Hope WW, Norton HJ, Lincourt AE, Millikan K, Fenoglio ME, Moskowitz M: Technique and outcomes of abdominal incisional hernia repair using a synthetic composite mesh: a report of 455 cases. J Am Coll Surg 2008, 206, 83-88.

[33] Bernard C, Polliand C, Mutelica L, Champault G: Repair of giant incisional abdominal wall hernias using open intraperitoneal mesh. Hernia 2007, 11, 315-320.

[34] Olmi S, Erba L, Magnone S, Bertolini A, Croce E: Prospective clinical study of laparoscopic treatment of incisional and ventral hernia using a composite mesh: indications, complications and results. Hernia 2006, 10, $243-247$.

[35] Berrevoet F, Fierens K, De Gols J, Navez B, Van Bastelaere W, Meir E, Ceulemans R: Multicentric observational cohort study evaluating a composite mesh with incorporated oxidized regenerated cellulose in laparoscopic ventral hernia repair. Hernia 2009, 13, 23-27.

[36] Balique JG, Benchetrit S, Bouillot JL, Flament JB, Gouillat C, Jarsaillon P, Lepère M, Mantion G, Arnaud JP, Magne E, Brunetti F: Intraperitoneal treatment of incisional and umbilical hernias using an innovative composite mesh: four-year results of a prospective multicenter clinical trial. Hernia 2005, 9, 68-74.

[37] Briennon X, Lermite E, Meunier K, Desbois E, Hamy A, Arnaud JP: Surgical treatment of large incisional hernias by intraperitoneal insertion of Parietex ${ }^{\circledast}$ composite mesh with an associated aponeurotic graft (280 cases). J Visc Surg 2011, 148, 54-58.

[38] Smietański M, Bury K, Tomaszewska A, Lubowiecka I, Szymczak C: Biomechanics of the front abdominal wall as a potential factor leading to recurrence with laparoscopic ventral hernia repair. Surg Endosc 2012, 26, 1461$-1467$.

[39] Langenbach MR, Schmidt J, Ubrig B, Zirngibl H: Sixty-month follow-up after endoscopic inguinal hernia repair with three types of mesh: a prospective randomized trial. Surg Endosc 2008, 22, 1790-1797.

[40] Biondi A, Tropea A, Monaco N, Musmeci G, Basile G, Basile F: Laparoscopic treatment of abdominal wall hernias: prosthesis material comparison Minerva Chir 2011, 66, 547-552.

\section{Address for correspondence:}

Aleksander Łukasiewicz

Department of Vascular Surgery

Regional Specialist Hospital

L. Rydygiera 15-17

86-300 Grudziądz

Tel.: 5664140 82, 5664140 89, 505836385

E-mail: alukasiewicz@wp.pl

Conflict of interest: None declared

Received: 18.10 .2012

Revised: 9.04.2013

Accepted: 20.02.2014 